\title{
La política de vivienda de la despolitización: gobernanza neoliberal, tecnocracia y luchas urbanas. El caso del Movimiento de pobladores Ukamau, Estación Central
}

The housing policy of depoliticization: neoliberal governance, technocracy and urban struggles. The case of the Ukamau Settlers Movement, Estación Central

\author{
Alex Paulsen Espinoza ${ }^{a}$ \\ ${ }^{a}$ Candidato a Doctor en Geografía, Instituto de Geografía, Pontificia Universidad Católica de Chile, Santiago, Chile. Correo \\ electrónico: appaulse@uc.cl
}

Historial del artículo Recibido:

28 de abril de 2020

Revisado

Investigación realizada gracias a Beca CONICYT Folio № 21181556.

16 de junio de 2020

Aceptado:

23 de junio de 2020

\section{Palabras clave}

Gobernanza, luchas urbanas, política de vivienda, tecnocracia, Ukamau

\section{Keywords}

Housing policy, governance, technocracy, Ukamau

\begin{abstract}
Resumen
La política de vivienda ha actuado como un sedante para los sectores vulnerados despolitizándolos y transformándolos en sujetos beneficiarios. Bajo un marco teórico que considera las características de la gobernanza urbana neoliberal con un enfoque en la tecnocracia que la caracteriza, este estudio trata de describir un caso en donde los pobladores se enfrentaron a dicha gobernanza neoliberal y su tecnocracia. Por medio de una metodología que consideró entrevistas semiestructuradas, etnografía participantes y datos desde organismos oficiales, los resultados demuestran que esta gobernanza neoliberal tecnocrática ha establecido intermediarios técnicos - como las Entidades de Gestión Inmobiliaria, EGIS- que han limitado y maquillado la participación de los pobladores. Además, un alto porcentaje de estas Entidades de Gestión Inmobiliaria realizan las actividades propias de la cultura tecnocrática: asesorías y consultorías. Asimismo, este estudio trata de dar cuenta de las estrategias llevadas a cabo por las familias de pobladores el movimiento Ukamau para enfrentarse a estos agentes, y que no solo fueron las protestas urbanas en el espacio público, sino que algo que fue más allá.
\end{abstract}

\begin{abstract}
The housing policy has acted as a sedative for the vulnerable sectors, depoliticizing them and transforming them into beneficiary subjects. Under a theoretical framework that considers the characteristics of neoliberal urban governance, with a focus on the technocracy that characterizes it, this study tries to describe a case where the inhabitants faced such neoliberal governance and its technocracy. Through a methodology that considered semi-structured interviews, participating ethnography and data from official organizations, the results show that this technocratic neoliberal governance has established technical intermediaries -such as the Real Estate Management Entities, EGIS- that have limited and made up the participation of the residents. In addition, a high percentage of these Real Estate Management Entities carry out the activities of the technocratic culture: consultancies and consultancies. Likewise, this study tries to account for the strategies carried out by the families of residents of the Ukamau movement to confront these agents, and that it was not only urban protests in public space, but something that went further.
\end{abstract}




\section{Introducción}

La oleada de rabia urbana ha sido uno de los movimientos societales más importantes en los últimos diez años en el mundo. Este tipo de fenómenos se ha dado precisamente en una era marcada por la urbanización incesante en todos los continentes. No obstante, no es menor señalar que este tipo de proceso involucra no solo a lo urbano como variable explicativa, sino que también a nuestros principales sistemas de convivencia y ordenamiento: la democracia. Como señala Dikeç (2017) al respecto, esta oleada de rabia urbana es parte de las fallas de las democracias liberales para abordar la exclusión. Una de estas fallas ha sido la histórica incorporación de cuerpos técnicos en los ámbitos de decisión, por sobre la participación de la ciudadanía, lo que agrava los problemas de exclusión. Esto no ha sido una excepción en Chile.

El 18 de octubre del 2019 se produjo en Chile una de las crisis políticas y sociales más importantes desde el retorno a la democracia. Esto luego de que el trasporte público aumentara sus tarifas a 830 pesos -1 USD- en la Región Metropolitana de Santiago a inicios del mismo mes. Esta decisión produjo una intensificación de las protestas urbanas que estudiantes secundarios venían haciendo desde inicios de octubre por medio de evasiones masivas al Metro de Santiago en diferentes estaciones. Esto generó una ola de rabia urbana en toda la región, la cual escaló a nivel de todo el país. Esta situación no se había visto antes en una sociedad despolitizada y con altos niveles de desafección política (Hipsher, 1996; Valdivia , 2013).

A primera hora de ese día, el gobierno de Chile manifestaba que esto era un problema asociado a grupos de delincuentes que se encontraban detrás de estas evasiones masivas (La Tercera, 2019). La prensa, en general, por medio de fotografías rimbombantes, daban cuenta de la quema de estaciones de metro junto a individuos encapuchados, como si se tratase de una escena completamente ficticia y recreada artificialmente (La Tercera, 2019). A pesar de esto, quienes habían decretado este aumento en la tarifa, se perdieron de vista y pasaron desapercibidos. Con esto nos referimos al grupo de tecnócratas que habían aprobado la nueva tarifa del sistema público de transporte. Luego serían llamados en general por la opinión pública como el "panel de expertos".

Este "panel de expertos" está compuesto de tres personas, que en un $100 \%$ provienen de una sola universidad nacional y tienen posgrados en el extranjero -ya sea en Estados Unidos o Inglaterra-. Este panel decide de manera unilateral la tarifa que afecta a una gran porción de habitantes de la Región Metropolitana de Santiago de Chile. Sin haber sido elegidos de manera democrática, este tipo de grupos tecnocráticos no solo han tenido influencia en el transporte, sino que también en vivienda, salud, trabajo y principalmente en la economía. La literatura los ha llamado "agentes no autorizados" por su bajo perfil, por no haber sido elegidos popularmente y por su alta influencia en las altas estructuras del Estado (Swyngedouw, 2011). Estos han tenido un rol importante en la configuración de la gobernanza urbana neoliberal y en las políticas de vivienda en general en Chile (Zunino, 2006). Sin embargo, su estudio ha quedado al debe en la literatura científica en general (Savini \& Raco, 2019).

La presente investigación pretende indagar en las relaciones existentes entre la gobernanza neoliberal, la tecnocracia y las luchas urbanas de las familias pobladoras por el acceso a la vivienda. En este sentido, esta crisis política y social confirmó una serie de desigualdades estructurales en términos de vivienda. Hay familias pobladoras que demoran hasta quince años o más en acceder a una solución habitacional, lo cual genera fenómenos de allegamiento histórico y con ello hacinamiento; procesos de postulación a programas de vivienda que por medio de los subsidios han individualizado el acceso (Alvarado 2019; Özler, 2012), desincentivando la conformación de comités de vivienda y allegados como alternativa para conseguir un lugar para vivir. Las políticas de vivienda y sus formas de postulación han sido creadas y configuradas precisamente por tecnócratas durante la dictadura cívico-militar-19731990- (Huneeus, 2016) y perfeccionadas durante los gobiernos posteriores con diferentes mecanismos -19902020- para despolitizar el conflicto social (Silva, 2010).

En este sentido, el título de esta investigación responde precisamente a lo que producen estas fallas de las democracias latinoamericanas al integrar a grupos tecnocráticos en sectores que involucra a un abanico de actores y agentes: despolitización (Dargent, 2015). Los procesos de despolitización responden precisamente a mecanismos sedantes e hipnotizantes hacia la sociedad (Swyngedouw, 2015). Luego del 18 de octubre, aquella sociedad sedada e hipnotizada de neoliberalismo urbano es la que devela una desigualdad ocultada por medio de los datos, índices y mediciones que tecnócratas nos habían entregado como sedantes durante cuarenta y cinco años.

En los siguientes capítulos se abordarán las formas de pensar la gobernanza neoliberal urbana desde América del Sur, considerando las características de las gobernanzas desde otras latitudes. Posteriormente, discutiremos sobre aquello que hemos llamado "tecnocracia urbana", sus 
definiciones, características y diferenciación con grupos, tales como burócratas y técnicos. En este sentido, el siguiente capítulo establece como las Entidades de Gestión Inmobiliaria -EGIS- son incluidas como parte del brazo tecnocrático en este panorama de la vivienda. Posteriormente, analizaremos el caso de estudio de los pobladores del Movimiento Ukamau y sus formas de acceso a la vivienda de manera colectiva. Este movimiento tiene sus raíces desde la década de 1980 y nace en Estación Central, particularmente en la población Santiago. A raíz de un diagnóstico de la situación de la vivienda en esta población se constituyen formalmente como comité de vivienda hacia el 2011. Desde entonces, su lucha por el acceso a la vivienda ha tomado diferentes estrategias y se han enfrentado a diferentes agentes.

Estas formas de acceso a la vivienda se han enfrentado a una serie obstáculos configurados entre la gobernanza neoliberal y tecnocracia urbana. Además de sortear una serie de normativas que son parte del entramado institucional y legal que tienen por objetivo disciplinar a los grupos sin vivienda. Esto más allá de las protestas y luchas urbanas que han puestos en escena en las principales arterias de la capital. El objetivo de esta investigación apunta a identificar a estos cuerpos tecnocráticos en general y en la institucionalidad de la vivienda en particular. La inclusión gradual de estos grupos ha constituido la instalación de un saber experto que excluye los conocimientos y prácticas de los pobladores en sus luchas por el acceso a la vivienda. Esto contribuye a establecer barreras de contención que actúan como procesos de despolitización que erosionan la democracia finalmente.

\section{Materiales y métodos}

Esta investigación se enmarca en un proceso de investigación doctoral en el cual se encuentra el autor entre el 2016 y el 2020. En este sentido, las entrevistas semiestructuradas realizadas se llevaron a cabo entre diciembre del 2016 y marzo del 2017, en el marco de la iniciación del proceso de inmersión a los movimientos de pobladores existentes en la Región Metropolitana de Santiago y luego en particular en el grupo del Movimiento de Pobladores Ukamau. Estas entrevistas se aplicaron a socios, voceros y dirigentes fundadores del movimiento, donde además se participó en sesiones y reuniones de las comitivas en la sede en la cual se reúnen. Dichas entrevistas giraron en torno a la formación de Ukamau, formas de lucha por el acceso a la vivienda y los agentes públicos y privados con los que deben interactuar. La posibilidad de asistir a sus reuniones nos dio la posibilidad de tomar registros etnográficos sobre los procesos de participación, formas de acción, así como también dinámicas particulares del grupo.

Para el caso de los grupos tecnocráticos que se han incorporado a los procesos de acceso a la vivienda, se ha construido una base de datos con las Entidades de Gestión Inmobiliaria -EGIS- existentes en la Región Metropolitana de Santiago a partir de datos aportados por el Ministerio de Vivienda y Urbanismo y los Servicios de Vivienda y Urbanización. Las EGIS fueron creadas en 1997 con el objetivo de que prestaran servicios de asistencia técnica y social a los pobladores que se encontraban en procesos de acceso a la vivienda bajo el programa de subsidio habitacional del Fondo Solidario de Vivienda (D.S. 174). Al 2018, y de acuerdo con esta base de datos, se registran cerca de 235 EGIS que no solo tienen como función primordial la de prestar asistencia técnica y social como giro principal de actividad económica, sino que su razón social remite a sociedades inmobiliarias, consultorías, entidades públicas y asesorías.

Además, hemos considerado la inclusión de Resoluciones legales desde las entidades encargadas de vivienda y urbanización, así como también datos cuantitativos provenientes de la Encuesta de Caracterización Social (CASEN) y el Censo de Población y Vivienda del 2017. En este último caso, hemos considerado particularmente los aspectos relacionados a vivienda, hacinamiento y el total del parque de viviendas en la comuna en estudio, es decir, Estación Central (figura 1).

Sumado a estos materiales, hemos dispuesto una serie de registros fotográficos que han sido parte de este trabajo de campo que se ha realizado entre el 2016 y el 2020. Estos registros se enmarcan en la visita al proyecto habitacional Condominio “Comunidad Ukamau I" en Estación Central (figura 2) y luego, planos (figura 3 y 4) de dicho proyecto que fueron tomados en Casa Ukamau en el marco de la muestra del proyecto piloto a los futuros residentes de este condominio y miembros del Movimiento Ukamau.

\section{Resultados}

Visiones de la gobernanza neoliberal urbana desde América del Sur

Desde un punto de vista amplio, la gobernanza urbana se relaciona con una constelación de agentes y actores que intervienen de diferente manera en la toma de decisiones y la elaboración de políticas urbanas en diferentes escalas. En Europa y América del Norte, con la aparición de agentes y actores en la escena urbana a partir de la 


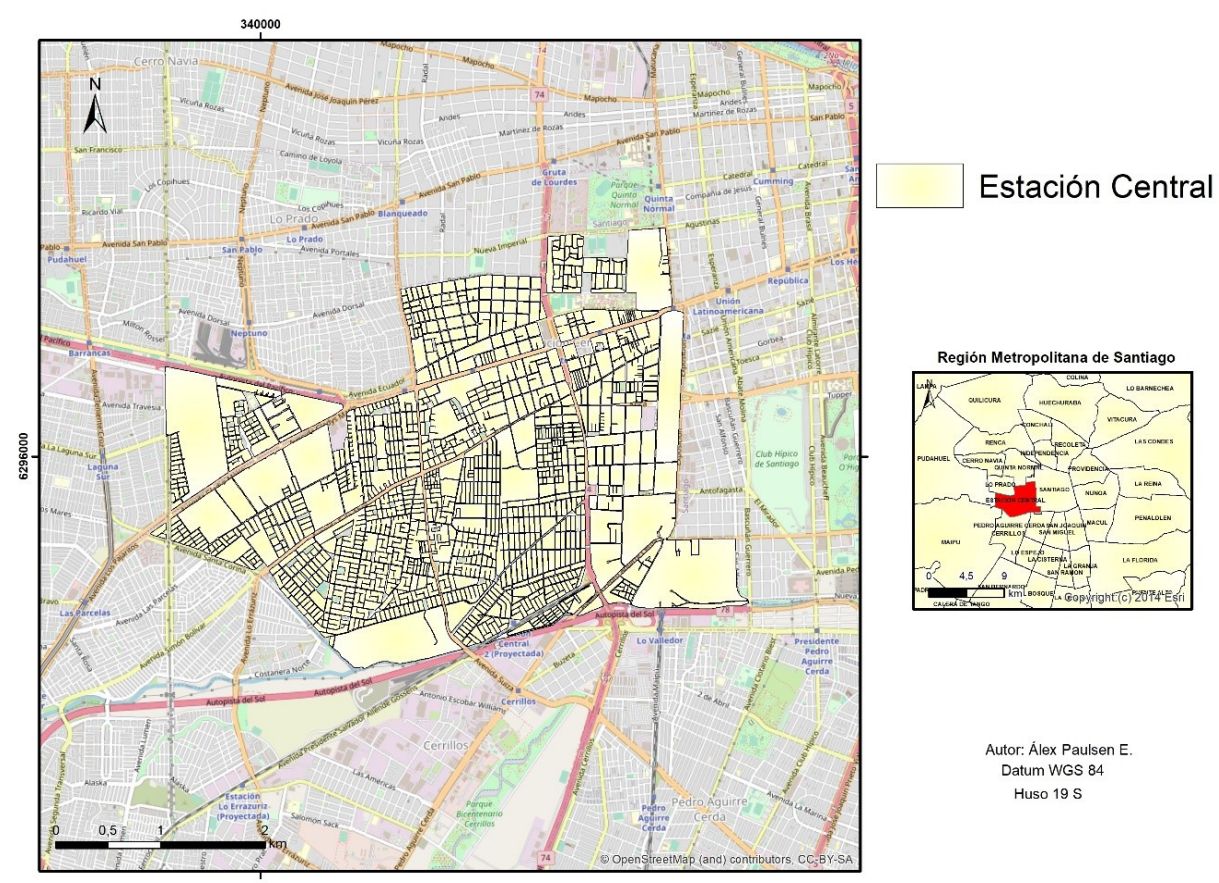

Figura 1. Localización del área de estudio. Fuente: elaboración propia.

década de 1970, se hace énfasis en que los asuntos del gobierno ya no se circunscriben a la administración. Esto implica a una nueva organización que involucra diferentes escalas -local, metropolitana, etc.- y cómo en estas los agentes y actores pretenden incidir. En América Latina, la gobernanza como concepto se aplica como un nuevo contexto político-administrativo que surge durante y posterior a los regímenes autoritarios (Sánchez, 2008).

Es un asunto complejo gobernar una ciudad, por lo que en la medida en que la economía se complejiza, los roles de la sociedad civil exigen mayor participación y los asuntos políticos cambian en la medida en que los contextos anteriores lo hacen. De esta manera, se hace necesaria la inclusión de agentes y actores no gubernamentales. Dicho esto, el enfoque de la gobernanza urbana se constituye en un proceso de coordinación social y dirección hacia objetivos colectivos (Pierre, 2014). Sumado a ello, este enfoque considera al poder en términos de resultados y no en autoridad formal. Esto significa que la materialización de los discursos y acciones nos indica que el poder se encuentra siendo ejercido por aquellos agentes o actores que lograron dichos resultados (Lukes, 2014; Pierre, 2014). En virtud de esto es que el enfoque de la gobernanza no postula o estipula ninguna fuente de poder político.
Resulta importante señalar que precisamente debido a la complejidad de gobernar la ciudad es que las contingencias en el espacio urbano dan señales al gobierno central, regional y local para definir objetivos, y formas de gobernanza urbana. Esto generó que debido a las exigencias económicas que comienzan a sentir las ciudades, el Estado central les otorga la posibilidad de integrar a otros agentes y actores tales como las ONG, sector empresarial, fundaciones, consultorías, técnicos, asesorías, grupos técnicos del Banco Mundial, organismos internacionales, entre otros (Swyngedouw, 2005, 2011). Esto ha llevado a evidenciar que las coaliciones entre agentes son menos institucionalizadas que en coaliciones especificas contextualmente definidas (Pierre, 2014). Estos agentes privados junto a los públicos establecen diferentes modelos de gobernanza urbana (Pierre, 1999) (tabla 1).

Como se puede evidenciar, los diferentes tipos de gobernanza no necesariamente se excluyen, sino que más bien estas pueden coexistir en una misma administración local o regional predominando ciertas prácticas por sobre otras. En América Latina, el retorno a la democracia significó la continuidad -en algunos casos como Chile, Colombiade las políticas neoliberales implementadas en este continente (Puello-Socarrás, 2015). En otros casos, las relaciones entre los regímenes autoritarios y la apertura 
Tabla 1

Tipo de gobernanza urbana, objetivos, participantes, instrumentos y resultados.

\begin{tabular}{|c|c|c|c|c|c|}
\hline $\begin{array}{l}\text { Tipos de } \\
\text { Gobernanza urbana }\end{array}$ & Objetivos & Participantes & Instrumentos & Resultados & Áreas de expresión \\
\hline Gerencial & $\begin{array}{l}\text { Mejorar eficiencia en la } \\
\text { creación y entrega de } \\
\text { servicios públicos }\end{array}$ & $\begin{array}{l}\text { - Participación } \\
\text { profesional. } \\
\text { - Funcionarios electos. } \\
\text { - Actores de la } \\
\text { sociedad civil. }\end{array}$ & $\begin{array}{l}\text { - Contratos con } \\
\text { organizaciones con } \\
\text { fines de lucro. } \\
\text { - Estrategias de } \\
\text { reclutamientos para } \\
\text { puestos claves. } \\
\text { - Redefinición de los } \\
\text { funcionarios electos. }\end{array}$ & $\begin{array}{l}\text { - Probable aumento } \\
\text { en la entrega de } \\
\text { servicios públicos } \\
\text { urbanos. } \\
\text { - Introducción de } \\
\text { experiencia del sector } \\
\text { privado al público. } \\
\text { - Relación de exclusión } \\
\text { con los actores de la } \\
\text { sociedad civil. }\end{array}$ & $\begin{array}{l}\text { - Europa } \\
\text { - América del Norte } \\
\text { - América Latina }\end{array}$ \\
\hline Corporativa & $\begin{array}{l}\text { Distributivo, asegurando } \\
\text { que los miembros de las } \\
\text { organizaciones formen } \\
\text { servicios y políticas } \\
\text { urbanas. }\end{array}$ & $\begin{array}{l}\text { Naturaleza participativa, } \\
\text { con participación masiva } \\
\text { a nivel intraorganiza- } \\
\text { cional; organizaciones } \\
\text { disfrutan de autoridad. }\end{array}$ & $\begin{array}{l}\text { Naturaleza inclusiva de } \\
\text { los instrumentos, incor- } \\
\text { porando la participación } \\
\text { de todos los agentes y } \\
\text { actores claves en los } \\
\text { procesos de formulación } \\
\text { de políticas urbanas. }\end{array}$ & $\begin{array}{l}\text { - Reduce la disciplina } \\
\text { fiscal, debido a la } \\
\text { presión de intereses } \\
\text { varios en el proceso } \\
\text { de participación. } \\
\text { - Relación inclusiva } \\
\text { con los actores. }\end{array}$ & $\begin{array}{l}\text { Pequeñas democracias, } \\
\text { industriales y avanzadas } \\
\text { de Europa. }\end{array}$ \\
\hline Crecimiento & $\begin{array}{l}\text { Crecimiento económico } \\
\text { sostenido y a largo } \\
\text { plazo. }\end{array}$ & $\begin{array}{l}\text { Elite política y altos } \\
\text { funcionarios; partici- } \\
\text { pación restrictiva para } \\
\text { no involucrar objetivos } \\
\text { distributivos. }\end{array}$ & $\begin{array}{l}\text { Planificación urbana; } \\
\text { movilización de recursos } \\
\text { del gobierno nacional y } \\
\text { regional; desarrollo de } \\
\text { infraestructura; cons- } \\
\text { trucción de una imagen } \\
\text { de ciudad para atraer } \\
\text { inversión; asociaciones } \\
\text { público-privadas institu- } \\
\text { cionalizadas. }\end{array}$ & $\begin{array}{l}\text { - Elección de } \\
\text { funcionarios } \\
\text { produce efectos } \\
\text { en la economía } \\
\text { local; cambios en la } \\
\text { economía nacional } \\
\text { tienen efectos en la } \\
\text { local. } \\
\text { - Relación de exclusión } \\
\text { con los actores. }\end{array}$ & $\begin{array}{l}\text { América del Norte; } \\
\text { América Latina. }\end{array}$ \\
\hline Bienestar & $\begin{array}{l}\text { Atraer y asegurar ingre- } \\
\text { sos nacionales para la } \\
\text { economía local a corto } \\
\text { plazo; redistribución e } \\
\text { interacción mínima con } \\
\text { capital privado. }\end{array}$ & $\begin{array}{l}\text { Funcionarios del gobier- } \\
\text { no local y burócratas } \\
\text { estatales; conexión en- } \\
\text { tre instituciones locales } \\
\text { y nacionales. }\end{array}$ & $\begin{array}{l}\text { Redes políticas y/o } \\
\text { administrativas con los } \\
\text { niveles superiores de la } \\
\text { administración estatal. }\end{array}$ & $\begin{array}{l}\text { - Se sostiene a largo } \\
\text { plazo. } \\
\text { - Relación inclusiva } \\
\text { con los actores. }\end{array}$ & $\begin{array}{l}\text { Europa; países escan- } \\
\text { dinavos. }\end{array}$ \\
\hline
\end{tabular}

Fuente: elaboración propia en base a Pierre (1999).

democrática significaron conflictos por la configuración de una orientación diferente -Bolivia- (Zibechi, 2007). En algunos casos, esto tuvo como consecuencia que las nuevas formas de gobernanza continuaran con las mismas orientaciones, ya fuesen gerenciales o de crecimiento, bajo la profundización de políticas neoliberales en todo nivel.

Estos modelos de gobernanza presentados en la tabla 1 son en la práctica altamente etnocéntricos. Los países desarrollados tienen diferentes capacidades institucionales, financieras y de administración en comparación a los países en vías de desarrollo o pobres (Sundaram \& Chowdhury, 2013). Esto no quita que los modelos señalados anteriormente tengan matices y ramificaciones en los países de América Latina. No obstante, deben ser señaladas las especificidades del continente latinoamericano. A nivel institucional, se menciona una fragmentación y situación estática de las instituciones frente a los cambios acontecidos en las áreas metropolitanas de creciente urbanización. La fragmentación se expresa en "intervenciones sectoriales o transversales desarticuladas, superpuestas e incluso contradictorias" (Arenas, 2008, p. 71; Pírez, 2008).

Con respecto a esta fragmentación institucional y la llegada de nuevos agentes, esto genera una dispersión de agentes e instituciones que tienden a atomizar las decisiones políticas y de representación. Esto ha configurado un desequilibrio de poder considerable entre los agentes públicos, privados y actores de la sociedad (Heinrichs, Nuissl \& Rodríguez, 2009; Lombard, 2013). Esto se traduce en que los actores de la sociedad civil no poseen las capacidades para enfrentar a los agentes del sector público y privado, los que desde 1990 en adelante han establecido alianzas con capacidades políticas y de recursos 
importantes para contener, y despolitizar a los actores de la sociedad civil, siendo los pobladores y juntas de vecinos actores relevantes a detener (Forray, 2007; Heinrichs et. al., 2009; Hipsher, 1996; Paley, 2001; Tapia, 2018).

A la par de la existencia de esta fragmentación institucional, lo que también acontece es la centralización del poder de regulación urbana en el gobierno central por sobre los gobiernos regionales y locales. Esto ha tenido como consecuencia una verticalización de las normas y las políticas urbanas (Sierra, 2006). Las políticas de vivienda y sus normas se decretan desde "arriba hacia abajo", es decir, desde los agentes públicos, los que tienen la potestad para establecer este tipo de normas en el contexto latinoamericano. En Chile, este tipo de verticalización es patente, a través de las atribuciones entregadas al gobierno central en materia de políticas urbanas y normas, ya que este tiene poder sobre los gobiernos regionales y locales en lo referido al cambio de las condiciones en los planes reguladores comunales hasta los seccionales (Sierra, 2006).

Por otro lado, y a la par con los desequilibrios de poder existentes en la ciudad latinoamericana en términos institucionales y de decisión, en términos financieros se tiende a replicar esta situación de inequidad en otros ámbitos (Pírez, 2008). En este sentido, lo social presenta necesidades de vivienda, equipamiento, infraestructura y servicios -entre otros- que se expresan en variados casos en la precariedad o la inexistencia de estos, en términos espaciales, en las comunas que no tienen mayores ingresos. En América Latina (Hidalgo, Brand \& Pérez, 2014; Lombard, 2013; Williams Montoya, Villarreal González \& Mignot, 2007), y particularmente en Chile, los municipios que cuentan con menores ingresos representan áreas donde se han concentrado históricamente poblaciones de clases sociales bajas y medias bajas (Arenas, 2008; Orellana, 2007). En contraposición, existen municipios que poseen una capacidad de tributación alta, lo que conlleva mejores condiciones urbanas en términos de equipamiento, infraestructura y políticas urbanas en general (Heinrichs et al., 2009).

En Chile, los inicios de una gobernanza de alianzas entre actores públicos y privados ya se comienzan a producir a mitad de la década de 1980. Esto bajo el contexto de los procesos de revitalización y renovación urbana de la comuna de Santiago. Más allá de las características de esta gobernanza, el contexto en el cual se comienzan a aplicar este tipo de gobernanza se da bajo condiciones autoritarias y de extrema represión en el cuerpo social y sobre todo de las familias pobladoras (Garcés, 2019; Murphy, 2015). Este contexto autoritario neoliberal desarrolló una gobernanza territorial que controlaba los espacios marginales de la ciudad, caracterizándose por la nula participación de los actores de la sociedad civil, su criminalización legal y política, persecución y exterminio (Sylvestre, Blomley \& Bellot, 2019).

Sylvestre, Blomley \& Bellot (2019) hacen un análisis de la criminalización legal desde la gobernanza hacia personas sin hogar, trabajadoras sexuales, drogadictos y movimientos sociales, pero bajo contexto democráticos -Canadá, Reino Unido y Estados Unidos-. América Latina representa un caso por el despliegue de dictaduras brutales, y en el caso de Chile, la más extendida y la que implanta un neoliberalismo en condiciones de excepción estatal (Hidalgo, Santana \& Alvarado, 2016). Esta gobernanza se contextualizó en un entramado de modificaciones que se iniciaron con la reestructuración del aparato estatal en la cual comenzaron a aparecer nuevas áreas administrativas, tanto a nivel regional como local (Bustos Gallardo, Lukas, Stamm \& Torre, 2019). Esto acentuó aún más los desequilibrios de poder entre los agentes públicos con los privados, y mayormente con los actores de la sociedad civil, lo que dio mayor preponderancia a algunos agentes privados por sobre los públicos y considerablemente hacia los actores urbanos.

Tecnocracia urbana y la despolitización de las luchas urbanas por la vivienda

En América Latina, la burocracia estatal había predominado la escena de las reparticiones públicas desde el siglo XIX hasta la década de 1960. No obstante, esta preponderancia de burócratas se comenzó a ver limitada con el ingreso de las ideas positivistas de la ciencia en la administración estatal en la segunda década del siglo XX en países como México -con Porfirio Díaz- y Chile -con Carlos Ibáñez del Campo- (Silva, 1997). Luego de cuarenta años de inclusión de científicos e intelectuales en el Estado, y con la aparición de los regímenes autoritarios en la década de 1960 en el continente latinoamericano, los tecnócratas comienzan a instalarse fuertemente en la toma de decisiones del Estado y la gobernanza urbana local.

Cuando hablamos de tecnocracia nos estamos refiriendo a un conjunto de agentes que, en virtud de su formación académica, constituyen no solo un cuerpo técnico, sino que también político al interior de entidades gubernamentales. Estos agentes pueden encontrarse al interior del Estado, como también afuera de él como parte de agencias privadas (Silva, 2010). Es necesario hacer la diferenciación que los tecnócratas no son solo cuerpos técnicos, así como tampoco burocráticos. Como señala Silva (2010), existen 
diferencias importantes entre los burócratas, técnicos y tecnócratas. El primero de ellos se define como un sujeto que solo "acata e implementa directrices legales que vienen desde arriba sin cuestionar su legitimidad o efectividad" (p. 23). El segundo de estos agentes, es decir, los técnicos, se asocian con grupos que tradicionalmente "se especializan en áreas sustantivas especificas tales como salud y agricultura, y generalmente gozan de seguridad laboral y contratos de largo plazo en reparticiones públicas tradicionales. Además, han recibido mayoritariamente su preparación técnica en centros tecnológicos y universidades nacionales" (Silva, 2010, p. 23).

A su vez, y como factor primordial, los técnicos en comparación con los tecnócratas carecen de la toma de decisiones, y su influencia es nula en los niveles políticos de quien toma dichas decisiones. Finalmente, los tecnócratas son calificados como "personas con un alto nivel de especialización académica, lo que constituye el principal criterio sobre la base del cual son seleccionados para desempeñar roles claves de toma de decisiones o consultorías en organizaciones grandes y complejas tanto públicas como privadas" (Silva, 2010, p. 22). Dicho esto, no es menor señalar que los tecnócratas son expertos con posgrados en universidades extranjeras y con experiencia internacional, operando en instituciones espacializadas de planificación y centros de estudio que tienen un perfil interdisciplinario, a diferencia de los técnicos.

Los estudios de la tecnocracia urbana han sido escasos tanto en el norte como en el sur global (Savini \& Raco, 2019). En América Latina, las relaciones entre estos grupos y los fenómenos urbanos se han enfocado en el desarrollo económico y el urbano (de Souza Cordovil \& Lúcia Rodrigues, 2010); la legitimación de desplazamientos y la producción de nuevas formas de pobreza urbana (Sims, 2015); participación y su tensión con la planificación tecnocrática neoliberal (Schatz \& Rogers, 2016; Zunino, 2014); exclusión étnica a partir de políticas urbanas de transformación de la ciudad (Garzón-Ramírez, 2018); el rol de la tecnocracia en el presupuesto participativo (Cabannes \& Lipietz, 2018); sus influencias políticas en proyectos urbanos (Zunino, 2006); y finalmente, las estrategias de transgresión de ciudadanos insurgentes frente a Estados tecnocráticos (Putri, 2019).

Desde el ámbito de la planificación de la ciudad, políticas urbanas y de vivienda, los tecnócratas tampoco han estado ausentes de su influencia tanto en el norte como en el sur global (Dikeç \& Swyngedouw, 2017; GarzónRamírez, 2018; Savini \& Raco, 2019). Estas políticas y programas son una forma de gobernar donde se han insertado estos cuerpos tecnocráticos precisamente para controlar y despolitizar a los ciudadanos que utilizan y ocupan un espacio determinado y evitar el conflicto (Swyngedouw, 2011, 2018). Esto por medio de un saber experto que se impone a través de datos, materialidades, redes y prácticas que producen objetos que se traducen en variadas políticas, las que, a su vez, se pueden formar de maneras inesperadas y que se unen a ideas e ideologías tales como la economía, el territorio, el estado, la ciudad, etc. En consecuencia, estas ideas pueden verse como objetos tecnocráticos (Prince, 2016).

Estos grupos comienzan un proceso de tecnocratización al tener una influencia decisoria en las estructuras altas del Estado, principalmente en la economía (Rumié Rojo, 2019). En la década de 1980, la presencia de los tecnócratas se hace patente en los países del continente, sobre todo en virtud de sus decisiones de ajustes estructurales -política monetaria- en el contexto neoliberal autoritario que reinó en la región (Silva, 2011). En países como Argentina, Brasil, Uruguay y Chile, la influencia de estos grupos tuvo un rol fundamental en la economía en estos regímenes autoritarios. Sin embargo, la excepcionalidad de Chile radica en que las acciones de estos grupos no solo se limitó a la economía, sino que a medida que pasaba el tiempo, estos "fueron expandiendo su influencia y autoridad a todas las esferas de la sociedad, incluyendo educación, salud, vivienda, el sistema de pensiones, los medios, etc." (Silva, 2010, p. 161).

De tal forma, en el caso de Chile, "al hacer uso de un discurso técnico y despolitizado, los tecnócratas lograron presentar sus políticas como instrumentos eficientes para transformar a los sectores populares en nuevos consumidores y fortalecer la economía del país" (Silva, 2010, p. 37). Esto iba en directa relación de contener y despolitizar a los grupos marginados de pobladores que abogaban por políticas urbanas y de vivienda inclusivas desde la década de 1960. Estos grupos tecnocráticos establecieron y dirigieron sus discursos hacia los grupos de poder que se habían instaurado bajo el régimen militar, es decir, los grupos económicos, los partidos políticos afines al régimen y a los mismos militares ${ }^{1}$ (Silva, 2010).

En el caso de Chile, las influencias tecnocráticas han sido decisivas en la generación de políticas públicas de vivienda

\footnotetext{
${ }^{1}$ Aunque estos últimos fueron altamente reticentes a las ideas de los tecnócratas debido a las visiones desarrollistas, estatistas y corporativistas que imperaban en los militares.
} 
y urbanas. Estos cuerpos tecno-políticos (Silva, 2010; Zunino, 2006) estuvieron presentes en la reestructuración del Ministerio de Vivienda y Urbanismo por medio de la Cámara Chilena de la Construcción (CChC) en 1965, la cual también influyó sobre la creación del subsidio habitacional en 1978 y que ya venía presionando desde 1974 para su formulación (Hidalgo, 2004). Constituida por un cuerpo de profesionales que se crea en la década de 1950, la CChC albergará a una serie de tecnócratas, profesionales y técnicos que tendrán influencia hasta el día de hoy en la formulación y puesta en marcha de políticas, planificación urbana y de programas de vivienda (Cofré, 2015; Hidalgo, 2004; Rubio, 2006).

En el caso de las políticas urbanas, los grupos tecnocráticos se han manifestado a partir no solo en sus alianzas con los agentes públicos encargados de dichas políticas, sino que también influyendo por sobre los actores de la sociedad civil y dichos agentes en la toma de decisiones en este ámbito. Como señala Zunino (2006), los marcos regulatorios urbanos establecidos en Chile durante la dictadura cívico-militar, sobre todo luego de 1979, favorecieron y promovieron el rol de los agentes tecnocráticos, además de la evaluación de las políticas y proyectos urbanos bajo criterios técnicos (Zunino, 2006). Como sigue este mismo autor, este fue el caso de lo acontecido con las regulaciones sobre las Áreas Urbanas Condicionadas (ZODUC) en 1997 y las Áreas Prioritarias de Urbanización (ADUP) en el 2004. Esto favoreció la extensión horizontal de la vivienda en general y su fragmentación en la RMS, además del rol preponderante de los agentes privados en estos procesos (Zunino, 2006).

Un caso particular en este sentido fue lo ocurrido en el Proyecto "Portal Bicentenario" (PB), en la comuna de Cerrillos, en lo que era el Aeródromo de esta municipalidad (Zunino, 2006). Con características de ubicación preferente, el proyecto $\mathrm{PB}$ representó una oportunidad de inversión desde los agentes privados y la consolidación de este paño urbano para los agentes públicos. Sin embargo, en las negociaciones entre los agentes públicos, privados y actores de la sociedad civil se generó un diferencial de influencia. Desde el Ministerio de Vivienda y Urbanismo -MINVU- se creó un Directorio encargado del proyecto, con el intendente de aquella época como director. Este directorio configurado por técnicos y supervisores de consultoras se encargó de realizar las reuniones de participación con los agentes y actores involucrados (Zunino, 2006).

En este contexto, la población involucrada quedó en desventaja producto de que los agentes locales -en una figura paternalista de hacer política- la representaban, pero, además, porque los agentes públicos fueron elevados en el cargo, pasando de un nivel operativo a uno de coordinación con cercanía al directorio supervisor. Esto provocó una desconexión mayor entre los agentes locales públicos con la población representada (Zunino, 2006).

La inclusión de tecnócratas en todo nivel, como en los ámbitos asociados a la planificación y políticas de vivienda y urbanismo ha tenido efectos en nuestro sistema político y social. El objetivo de estos grupos radicó en la conformación de una ideología tecnocrática que "se ha mezclado con la idea democrática en Chile, con lo cual se ha ido constituyendo un régimen democrático tecnocratizado y crecientemente despolitizado, en la cual los problemas sociales tienden a ser traducidos a términos técnicos y enfrentados a través de políticas públicas de corte tecnocrático" (Silva, 2010, p. 39).

En consecuencia, la incorporación de los tecnócratas en Chile no solo configuró una nueva racionalidad de hacer las políticas públicas -amparada bajo la eficiencia y la optimización de procesos-, sino que esta se incardinó en la institucionalidad y cultura misma hasta llegar a las bases de la democracia hoy en día. Esto excluyó los saberes populares de las familias pobladoras que venían luchando por la vivienda desde la década de 1940 en Chile, y particularmente en la Región Metropolitana de Santiago.

Gobernanza tecnocrática-neoliberal en vivienda: las Entidades de Gestión Inmobiliaria

Como nos hemos referido en la tabla 1, los tipos de gobernanza se refieren a una serie de características que involucran a actores, participación, prestación de servicios, distribución de recursos y los instrumentos utilizados. Durante la década de 1980, las transformaciones en la economía global hacían una presión sobre las ciudades como nodos de crecimiento económico por sobre las regiones y naciones (Sassen, 1998). Particularmente, en la Región Metropolitana de Santiago, se comenzaban a dar alianzas público-privadas promovidas por entes públicos para incentivar a la oferta en la renovación urbana y desarrollo inmobiliario (Paulsen-Espinoza, 2014). Estas transformaciones en la gobernanza urbana ocurrieron en América Latina durante y después de las dictaduras que asolaron al continente (Sánchez, 2008).

Durante la década de 1990, las modificaciones a las políticas de vivienda se insertaron en un contexto de exitismo generalizado de estas. En este sentido, una de las modificaciones que profundizan la participación de agentes urbanos privados tecnocráticos y técnicos viene 
dado por las Entidades de Gestión Inmobiliaria (EGIS). De acuerdo con la Resolución 533 promulgada en octubre de 1997, se establece que las EGIS serán “personas jurídicas, de derecho público o privado, con o sin fines de lucro, que prestan los servicios de asistencia técnica y social que se señalan (...) para el programa Fondo Solidario de Vivienda" (Resolución 533, 1997, p. 1). El Servicio de Vivienda y Urbanismo -SERVIU- se encargará, según dicha resolución, de financiar a estas EGIS y además contratarlas.

Las labores por desarrollar por parte de estas EGIS estarán dadas según las tipologías de proyectos a aplicar. En la modalidad A, que se refiere a la Asistencia Técnica y Social a la construcción de viviendas, las EGIS se encargarán de a) organizar la demanda, obtención de la personalidad jurídica del grupo y la gestión de todos los antecedentes del grupo postulante; b) elaboración de proyectos técnicosconstructivos, lo cual implica los de urbanización, loteo del conjunto, arquitectura y estructura de la vivienda; c) el Plan de Habilitación Social posterior a la selección, que significa cumplir con las actividades señaladas en el Plan de Habilitación Social presentado y aprobado por el SERVIU; d) gestión legal y administrativa del proyecto que implica la realización de todas las actividades que significa el proceso de postulación y adquisición del proyecto (Resolución 533, 1997).

En la modalidad B, que se refiere a la Asistencia Técnica y Social a la Adquisición de Viviendas Existentes, las EGIS deben realizar las siguientes acciones: a) identificación de la vivienda a la que aplica el subsidio, tasación, estudio de títulos, análisis de adquisición, redacción de la promesa y contrato de compraventa, trámites notariales y de inscripción en el Conservador de Bienes Raíces, y la ejecución del plan de Habilitación social; b) suscribir con el MINVU el Convenio Marco; c) presentar al SERVIU un proyecto de asistencia técnica y social, el cual será seleccionado y financiado por esta entidad pública; d) proveer los servicios de asistencia técnica y social necesarios para asegurar la correcta ejecución del proyecto; e) además de las actividades que se especificaron en las letras a, b, c y d de la Modalidad A (Resolución 533, 1997).

En la actualidad, del total de EGIS registradas en el MINVU y SERVIU, el 14,4\% corresponde a entidades de carácter público asociadas a municipalidades principalmente ${ }^{2}$. El restante $85,5 \%$ corresponde a entidades privadas asociadas a asesorías, consultorías, constructoras, inmobiliarias, sociedades, fundaciones, cooperativas y empresas de arquitectura. De estas entidades privadas, el 37,1\% tienen su sucursal principal o casa matriz, declarada en este registro, en Santiago, seguido de un 13,8\% en Providencia y un 5,9\% en Las Condes. Estas son las tres ubicaciones con mayor cantidad de sucursales de EGIS privadas en la Región Metropolitana de Santiago de Chile.

Desde 1997, estas EGIS han actuado como intermediarias entre los postulantes a subsidios habitacionales en las modalidades antes mencionadas en los programas de viviendas sociales de sectores vulnerados. Con ello, los agentes privados se han establecido como intermediarios entre las familias pobladoras y los entes públicos encargados de la vivienda. En consecuencia, estos últimos han delegado funciones públicas a estos agentes privados, los cuales han proyectado una visión de eficiencia y optimización de los procesos de postulación en estos programas, pero sin la participación de las familias de pobladores. El movimiento de pobladores Ukamau, cuestionando este tipo de intermediarios y procesos, establece otra ruta de acceso a la vivienda que no considera a este agente privado.

\section{El movimiento de Pobladores Ukamau y sus luchas con la gobernanza tecnocrática neoliberal.}

El Movimiento de familias pobladoras UKAMAU -que en aimara significa "Así somos"- nace en la Población Santiago, en Estación Central. En dicho lugar se habían congregado un conjunto de jóvenes en 1984 para comenzar un centro cultural que habían llamado Hue Huentru. Luego, el 30 de abril de 1987 se originará el grupo llamado Agrupación de Talleres Culturales UKAMAU, gracias a los aportes que realiza una ONG sueca ligada a la doctrina de la Iglesia Metodista. Con dichos aportes fue posible adquirir la actual casa UKAMAU. Durante los ochenta, esta agrupación lleva a cabo una serie de actividades culturales que tienen por objetivo ser acciones de resistencia frente a la dictadura cívico-militar (1973-1990).

En la primera década del siglo XXI, la agrupación comienza a realizar un catastro para verificar cuáles eran las urgencias de los vecinos de la población Santiago. Los resultados de este diagnóstico arrojaron que la vivienda era un tema urgente, sobre todo para las familias que se encontraban en situación de allegados. Según la Encuesta CASEN de 1990, el 35,4\% de las viviendas de Estación Central

${ }^{2}$ Dichas entidades corresponden a las municipalidades de: La Florida, Lo Espejo, Lo Prado, Peñalolén, Puente Alto, Recoleta, Cerro Navia, Pedro Aguirre Cerda, La Pintana; Colina, Independencia, Curacaví, Maipú, El Bosque, Quilicura; Macul, San Pedro, La Reina, Melipilla, Huechuraba, San Miguel, Buin, Ñuñoa, Santiago, Las Condes, La Granja, Lo Barnechea, Estación Central, El Monte, San Ramón, Talagante, Renca, Peñaflor y Conchalí. 
tenían dos hogares (Gobierno de Chile - Ministerio de Planificación, 1990). Posteriormente, la misma encuesta devela que hacia el 2000 esto se traducía en un 3,8\% de viviendas con la misma cantidad de hogares (Gobierno de Chile - Ministerio de Planificación, 2000), para luego aumentar a un 12\% en el 2017 (Ministerio de Desarrollo Social y Familia, 2017). Según el censo del 2017, en Estación Central existían 5.186 viviendas con hacinamiento medio $^{3}$ y crítico, lo que representaba un $11,8 \%$ del total del parque de viviendas de esta comuna (Observatorio Urbano, 2017).

Frente a este contexto, conforman un comité de vivienda en el año 2011 que pudiese dar solución a esta realidad. Sus peticiones fueron en primer lugar conseguir vivienda en el mismo lugar en el cual habían desarrollado sus historias de vida; $y$, en segundo lugar, querían un proyecto que atendiese a sus necesidades, tales como cercanía a sus fuentes laborales, viviendas con metros cuadrados que aseguraran un amplio espacio, equipamiento e infraestructura como áreas verdes, estacionamientos, lugares de recreación, entre otros. Con estos objetivos en mente, el comité comenzó la búsqueda de un terreno para el proyecto. Esto se concretó con un terreno en la Maestranza San Eugenio de la Empresa de Ferrocarriles del Estado -EFE- en las intersecciones de las avenidas Exposición y Ramón Subercaseaux en Estación Central. Sin embargo, los problemas con dicho terreno, produjo enfrentamientos con la gobernanza tecnocrática neoliberal. Como nos señala una socia fundadora de Ukamau:

al comienzo la Maestranza no se podía vender, porque era de ferrocarriles del Estado, entonces el Estado no le podía vender al Estado, pero al final no era del Estado, sino que era particular y ahí empezamos a ver las leyes y claro, ferrocarriles había vendido en otro lugar, si hubo jurisprudencia, si ya se hizo una vez, podía ser dos veces... (socia fundadora Ukamau, 2017)

El terreno de La Maestranza San Eugenio ofrecía una ubicación óptima para las familias pobladoras. Su localización permitía estar en los espacios donde ellos tenían sus historias personales, una accesibilidad a las principales arterias de la capital -Alameda Libertador Bernardo O'Higgins- y transporte público -estaciones de Metro en línea 1, 2 y 6-. Sin embargo, el proceso de adquisición de este terreno fue una interposición de trabas, unas tras otras, desde entidades como el SERVIU hasta las interferencias del capital inmobiliario y sus intereses en construir en este sector ${ }^{4}$.

Un episodio en este proceso se produce en las conversaciones entre los pobladores y las autoridades municipales. Como nos relata una pobladora de UKAMAU, cuando la agrupación solicita el terreno de La Maestranza San Eugenio a la Municipalidad de Estación Central, una de las autoridades responde, "ustedes quieren La Maestranza San Eugenio, entonces yo me voy a comprar la Torre Entel (...)" (socia fundadora Ukamau, 2017).

Esta última frase que le dirige un agente público a una pobladora daría cuenta de las escasas expectativas que proyecta la tecnocracia neoliberal ante pobladores que autogestionan sus viviendas. Otra investigación ha dado cuenta de situaciones similares hacia los pobladores, desde los agentes técnicos públicos. Como señala Correa (2017) citando la frase de unos de estos técnicos al referirse a la autogestión de los pobladores: "No es un modelo replicable, porque en general los comités no tienen las capacidades técnicas que se requieren para desarrollar un proyecto" (Correa, 2017). El conocimiento técnico impera sobre los saberes populares en sociedades "tecnocratizadas" como la chilena.

Por su parte, el SERVIU señaló que terrenos del Estado no podían ser vendidos al mismo Estado. No obstante, los pobladores identificaron que ya había existido una transferencia de este terreno de parte de EFE, y que además no era propiedad fiscal. Una de las narraciones que relatan los dirigentes y socios en este contexto es que, debido a la negativa del SERVIU, elaboraron una estrategia para ver el acceso a este terreno. Esta estrategia se fundamentó en el hecho de que el comité se hizo pasar por una empresa inmobiliaria y enviaron una oferta a EFE mostrando el interés de comprar el terreno de La Maestranza. La entidad pública aceptó la oferta.

Con respecto a la posibilidad de contratar una EGIS, el comité mostró su desconfianza a estas entidades, pero también, conocieron los beneficios de no contar con este tipo de intermediarios. Como señala una pobladora al respecto,

\footnotetext{
${ }^{3}$ Hacinamiento medio se refiere a la existencia de entre 2,5 y menos de cinco personas por dormitorio; y hacinamiento crítico a más de cinco personas por dormitorio o sin este.

${ }^{4}$ Sobre todo, considerando la construcción y puesta en marcha de la actual línea 6 del Metro de Santiago.
} 


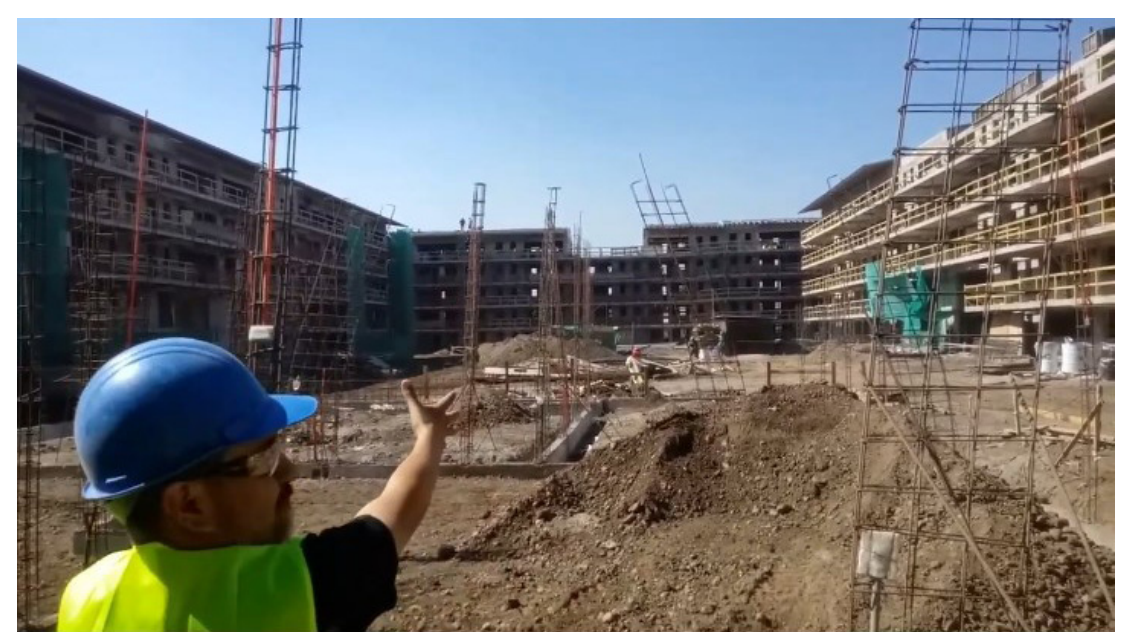

Figura 2. Construcción Proyecto Condominio “Comunidad Ukamau l”, Estación Central. Fuente: autor, 2019.

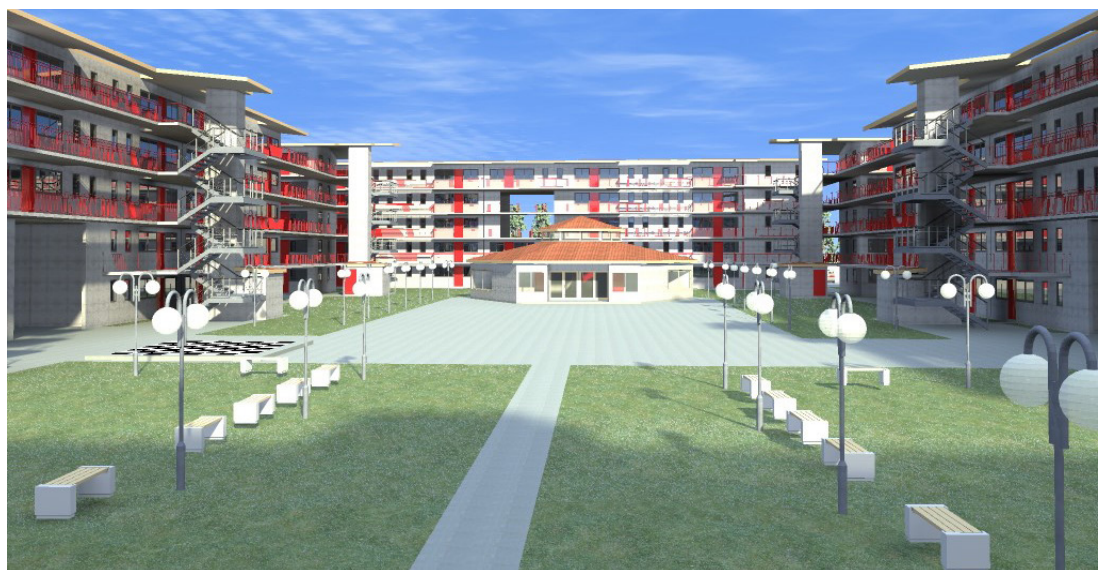

Figura 3. Proyección maqueta final Proyecto Condominio "Comunidad Ukamau I", Estación Central. Fuente: archivos del Movimiento de Pobladores Ukamau.

otros comités tampoco luchan por la vivienda, sino que van a las reuniones, $\mathrm{y}$ todas las gentes le hacen los papeles, los dirigentes son una EGIS, que al final es una institución, una empresa... acá todo los hacemos nosotros, también le enseñamos a los socios, cuando empezamos las primeras postulaciones necesitábamos socios, les decíamos, ya tienes que ir a arreglar los papeles, entonces se le enseñaba a la gente como era su postulación, aquí van a ir los papeles, de esta forma, de este orden, entonces la gente sabe cómo hacer los temas, no es que le hicieran la pega, entre todos se hace la pega, todos sabemos cómo se hace el trabajo. (socia fundadora Ukamau, 2017).
En esta misma dirección, otra pobladora agregó al respecto, "porque la EGIS les cobra a los miembros del comité, y les hace todo el papeleo...y nosotros no tenemos EGIS..." (socia Ukamau, 2017).

De esta manera, la autogestión por parte de los pobladores comenzó por eliminar la representación desde la Entidad de Gestión Inmobiliaria Social (EGIS), con lo que los metros cuadrados aumentaban en $6 \mathrm{~m}^{2}$ para las viviendas sociales (pasando de $55 \mathrm{~m}^{2}$ a $62 \mathrm{~m}^{2}$ ). Luego, solicitaron la ayuda de los arquitectos de la oficina de Fernando Castillo Velasco. En constantes asambleas, pobladores $\mathrm{y}$ arquitectos conformaron el proyecto que se encuentra hoy en día en construcción en La Maestranza San Eugenio (figura 2 y 3 ). 


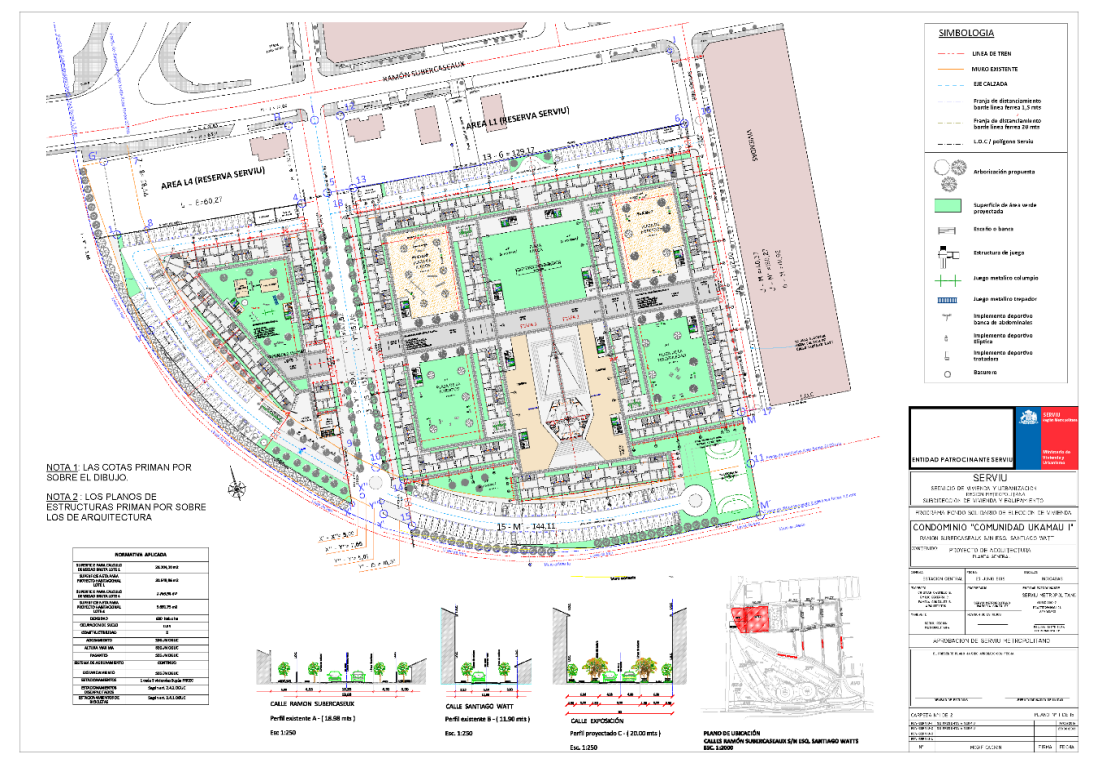

Figura 4. Proyecto Condominio "Comunidad Ukamau I". Fuente: SERVIU - Región Metropolitana - Sub-Dirección de Vivienda y Equipamiento.

Es menester señalar que la constructora que gana la licitación para la construcción de este proyecto tuvo demoras en el proceso y finalmente tuvo que ser depuesta por el SERVIU. Esto significó un retraso en las obras debido a la búsqueda de una nueva empresa constructora, y con ello todo el proceso de instalación. Esta situación no solo implica una demora en el término del proyecto, sino que también una forma de espera a la cual deben someterse las familias vulneradas en el acceso a la vivienda en general (Koppelman , 2018). Dicha espera se ha traducido en cerca de diez años para acceder a este conjunto habitacional.

\section{El Triunfo: "todavía no se compra la Torre Entel y nosotros estamos a punto de que nos construyan" 5}

La frase que encabeza este acápite refleja el triunfo de las familias pobladoras que, por medio de constantes luchas urbanas en el espacio público y una preparación como grupo, doblegaron esta gobernanza tecnocrática neoliberal. El movimiento de las familias Ukamau logró adquirir este terreno sin la intermediación de una EGIS, y con el apoyo de la oficina de arquitectos Castillo-Velasco, particularmente bajo la proyección y supervisión de los arquitectos: Cristian Castillo, Pamela González y Emilio
Becerra. Junto a estos últimos, realizaron un proceso de participación en la elaboración del proyecto arquitectónico y de los espacios interiores de este. Estos conjuntos de viviendas sociales albergarán a más de 400 familias en 320 departamentos de $62 \mathrm{~m}^{2}$ (figura 4).

Sus obras se iniciaron el 21 de noviembre del 2017 y se proyecta que finalicen durante el año 2020. La inversión realizada en este proyecto representa un total de 435.292,72 Unidades de Fomento -U.F.- ${ }^{6}$. Las áreas verdes interiores se proyectaron hacia el interior de los edificios de departamentos para tener la visibilidad de los niños durante sus juegos. Los departamentos tienen la posibilidad de ampliar y fusionar la cocina con el estar/ comedor de la vivienda, por medio de un tabique que se puede eliminar sin problemas. Al centro del principal espacio de esparcimiento del conjunto habitacional, se proyectará y construirá la sede social que albergará a las familias pobladores en sus diversas reuniones. Los departamentos se encuentran tipificados en cuatro tipos, los cuales tienen tres dormitorios, un baño, estar/ comedor, logia y en algunos casos un balcón integrado a la vivienda (figura 5).

${ }^{5}$ Declaraciones de una pobladora del Movimiento Ukamau.

${ }^{6}$ Las Unidades de Fomento es un índice de reajustabilidad, calculado y autorizado por el Banco Central de Chile, para las operaciones de crédito de dinero en moneda nacional que efectúen las empresas bancarias y las cooperativas de ahorro y crédito. En Chile, las transacciones de viviendas en general se encuentran ajustadas a esta unidad. El monto señalado representa un total de (USD) 14 millones de dólares. 

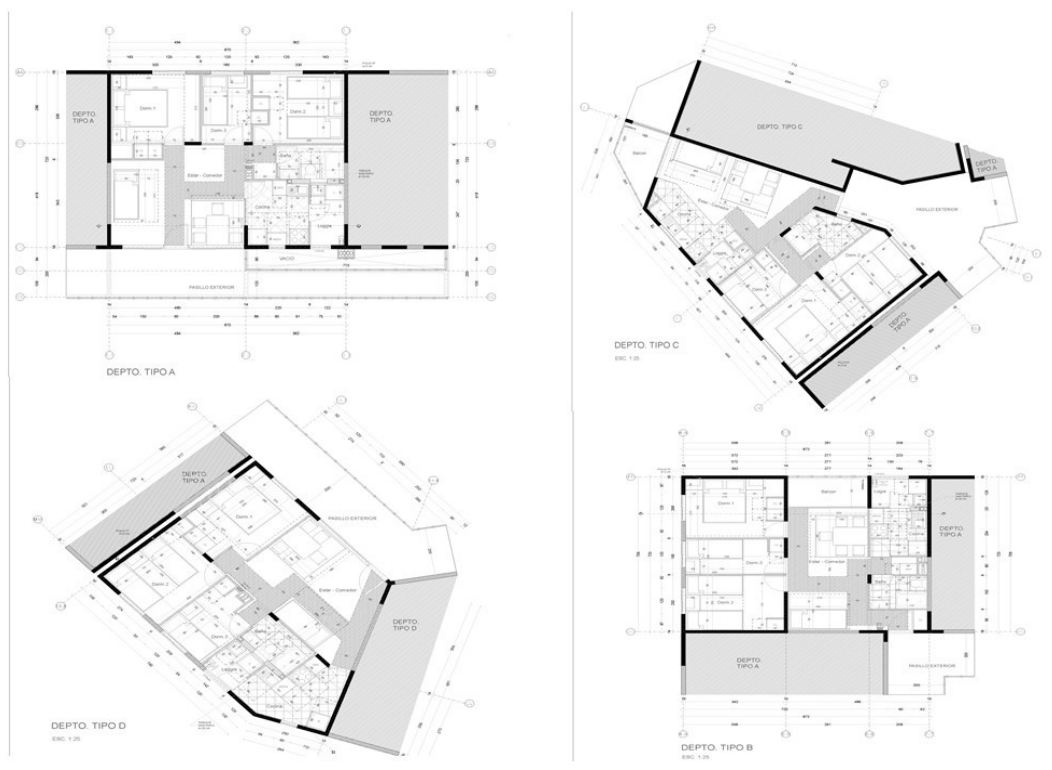

Figura 5. Tipología de departamentos "Comunidad Ukamau I". Fuente: SERVIU - Región Metropolitana - Sub-Dirección de Vivienda y Equipamiento.

La proyección de este proyecto de vivienda no fue solo obra de un conjunto de profesionales que aplicaron sus conocimientos en términos urbanísticos, estructurales, arquitectónicos y de vivienda en general. Este fue un proceso en el cual cada uno de los actores y agentes involucrados jugó un rol fundamental. Sin embargo, la participación de las familias pobladores fue fundamental. Esto significó involucrar desde los adultos mayores hasta los niños en el diseño de los espacios que los albergará a partir del 2020 para el resto de sus vidas. Cada espacio del proyecto Condominio "Comunidad Ukamau I" tiene su explicación, desde los colores de las puertas de los departamentos, pasando por los pasillos, la localización de los shaft de basura, los pasillos de circulación e incluso la asignación de las viviendas a cada una de las familias. La idea que une todos los espacios es una: seguir creando comunidad.

\section{Conclusiones}

El proyecto neoliberal se instaló en Chile bajo sus propias premisas normativas, institucionales y políticas. Estas premisas se impusieron y se proyectaron en la cultura nacional, y en general en todos los ámbitos de nuestra sociedad. De igual modo, este proyecto ideológico tenía en sus bases eliminar todo tipo de conflicto social en los normales procesos de disputa que en toda sociedad deben existir (Paley, 2001). Para ello, se debía establecer un consenso generalizado en la sociedad que nos llevará a pensar que las decisiones debían ser tomadas de manera racional, eficiente y óptima, bajo parámetros técnicos y criterios configurados por expertos. Esto inauguró un proceso de despolitización que se instaló en la economía, pasando por la educación, salud hasta en la vivienda. La democracia profundizó este proceso y como señala Zibechi (2010) fue el inicio de la "domesticación de los conflictos sociales".

Para constituir dicho proceso, se establecieron alianzas que privilegiaron a los entes privados en su rol de proveer los servicios necesarios, limitar los procesos participativos y señalar que su conocimiento "experto" era el que sabía (Zunino, 2014). Esto fue el comienzo de la gobernanza tecnocrática neoliberal, que se inaugura en la década de 1980 y que ha proseguido hasta hoy. Se denominó "tecnocracia" a aquellos expertos que debido a su formación profesional e influencia política lograron ingresar a las altas esferas del Estado. Su racionalidad los llevó a configurar políticas como los subsidios habitacionales, programas barriales hasta la creación de las Entidades de Gestión Inmobiliaria en la década de 1990. Precisamente a partir de esta década es que las asesorías y consultorías se aliaron con los entes públicos para llevar a cabo el combate contra la pobreza y las familias que eran vulneradas por el sistema neoliberal. 
Sin embargo, estas políticas configuraron a un tipo de sociedad que manifestó abiertamente su exclusión a los saberes populares y creyeron en las racionalidades técnicas de estos nuevos agentes. Como hemos visto, la gobernanza tecnocrática neoliberal se instaló y aplicó estas políticas precisamente para limitar la participación y despolitizar a la sociedad que se encontraba excluida. Esto con el objetivo de no generar alteraciones en un orden social que se vanagloriaba por su irrestricto apego a las leyes, alto crecimiento económico, infraestructura avanzada y, sobre todo, su institucionalidad a prueba de todo. Estos mitos se rompen luego del 18 de octubre y el quiebre neoliberal se triza profundamente. La vivienda y las familias pobladoras eran un punto central de estas desigualdades y de este quiebre, tal como lo ocurrido con las protestas nacionales de la década de 1980.

Ukamau representa un caso al revitalizar las luchas urbanas por la vivienda durante la primera década del siglo XXI, junto a otros movimientos de familias pobladoras en la Región Metropolitana de Santiago. Frente a las indolentes respuestas de esta gobernanza tecnocrática neoliberal, deciden crear un comité de vivienda para solucionar los problemas de allegamiento y hacinamiento en su sector. Casa UKAMAU se transformó en un lugar de congregación de pobladores para organizar las jornadas de luchas urbanas, así como también para llevar a cabo las asambleas en las cuales los miembros de los comités de viviendas van formalizando su postulación a una vivienda. Asimismo, este espacio también ha sido catalizador de una cultura contrahegemónica por medio de la educación popular y la formación de dirigentes de otras agrupaciones de comités de vivienda?. Esto podría ser el símil de "La Noche de los proletarios" de la cual habla Rancière (2010), donde la organización de un grupo de obreros durante las noches los llevó a pensar y discutir sobre temas que su vida de trabajo no les había permitido en su diario vivir.

Esto preparó el camino para comprender que el neoliberalismo urbano se sustenta en un entramado legal (Vicuña, 2013) que controla, pero, sobre todo, despolitiza a quienes se han convertido en sujetos beneficiarios y no en sujetos de derecho. Las familias pobladoras de Ukamau comprendieron que este entramado se debía aprehender para luego luchar por los derechos que no se deben ajustar a fichas de protección social, encuestas de caracterización socioeconómica, entre otras creaciones tecnocráticas que solo apuntan a la pobreza como problema, pero no a la riqueza. En este contexto, su lucha les permitió acceder a viviendas donde habían desarrollado su vida, así como también sus fuentes laborales, escuelas, centros universitarios, transporte, salud y, sobre todo, una historia, a pesar de la política de vivienda de la despolitización.

\section{Referencias}

Alvarado, V. (2019). El aporte de los subsidios en la contención del conflicto socio-habitacional metropolitano. Del apoyo mutuo al consumo perpetuo en Santiago de Chile (1980-2014). Revista CIS, XVI (27), 35-47. Recuperado de https://revistacis.techo. org/index.php/Journal/article/view/185/162

Arenas, F. (2008). Obstáculos para la gobernanza de los espacios metropolitanos chilenos: fragmentación institucional, desarticulación instrumental, atomización social. En G. Yáñez, A. Orellana, O. Figueroa \& F. Arenas, Ciudad, Poder, Gobernanza (pp. 67-75). Santiago de Chile: Serie GEOlibros - Instituto de Geografía - Pontificia Universidad Católica de Chile.

Bustos Gallardo, B., Lukas, M., Stamm, C. \& Torre, A. (2019). Neoliberalismo y gobernanza territorial: propuestas y reflexiones a partir del caso de Chile. Revista de Geografia Norte Grande, 73, 161-183. http://dx.doi.org/10.4067/S071834022019000200161

Cabannes, Y., \& Lipietz, B. (2018). Revisiting the democratic promise of participatory budgeting in light of competing political, good governance and technocratic logics. Environment and Urbanization, 30(1), 67-84. http://dx.doi. org/10.1177/0956247817746279

Cofré, B. (2015). El sueño de la casa propia: Estado, empresarios y trabajadores ante el problema de la vivienda y urbanización residencial. Santiago de Chile. 1952 - 1973 (Tesis para optar al grado de Doctor en Historia). Santiago de Chile: Pontificia Universidad Católica de Chile - Instituto de Historia.

Correa, Cecilia. (11 de agosto de 2017). Las últimas viviendas autogestionadas. Qué Pasa. Recuperado de http://www.quepasa.cl/articulo/actualidad/2017/08/ las-ultimas-viviendas-autogestionadas.shtml/

${ }^{7}$ A partir del 2018, UKAMAU convoca a diferentes agrupaciones de comités de viviendas, allegados, sindicatos que luchan por su vivienda, entre otros, para conformar el Frente de Resistencias Urbanas. Su objetivo es "el cambio estructural del sistema político, económico y social, que permita salir del neoliberalismo primero y del capitalismo después, a la vez que ir sentando las bases de un sistema que podamos llamar "la vida buena" (Frente de Resistencias Urbanas, 2018). 
Dargent, E. (2015). Technocracy and Democracy in Latin America. The Experts Running Government. New York: Cambridge University Press. Recuperado de https://doi.org/10.1017/CBO9781107446663

de Souza Cordovil, F. \& Lúcia Rodrigues, A. (2010). Da tecnocracia à participação popular: A institucionalização e os novos rumos do planejamento urbano em Maringá, Paraná, Brasil. Scripta Nova. Revista Electrónica de Geografía y Ciencias Sociales, 14(331). Recuperado de http://www.ub.es/geocrit/sn/ sn-331/sn-331-40.htm

Dikeç, M. (2017). Urban Rage. The revolt of the excluded. New Haven: Yale University Press.

Dikeç, M. \& Swyngedouw, E. (2017). Theorizing the politicizing city. International Journal of Urban and Regional Research, 41(1), 1-18. https://doi. org/10.1111/1468-2427.12388

Forray, R. (2007). Participación. Compartir los poderes de decisión y acción sobre la ciudad. En M. Castillo, \& R. Hidalgo, 1906/2006. Cien años de política de vivienda en Chile (pp. 129-149). Santiago de Chile: Ediciones UNAB - Serie Arquitectura $\mathrm{N}^{\circ} 1$ - Serie GEOlibros $N^{\circ} 10$ - Facultad de Arquitectura y Diseño UNAB - Instituto de Geografía.

Frente de Resistencias Urbanas. (2018). Quiénes somos. Santiago.

Garcés, M. (2019). Pan, trabajo, justicia y libertad. Las luchas de los pobladores en dictadura (1973-1990). Santiago de Chile: LOM.

Garzón-Ramírez, S. (2018). Unveiling the technocracy of a global South City. Gender, Place and Culture, 25(4), 607-611. http://dx.doi. org/10.1080/0966369X.2018.1461078

Gobierno de Chile - Ministerio de Planificación. (1990). Casen 1990 - Encuesta de Caracterización Socioeconómica Nacional. Santiago de Chile: Gobierno de Chile. Recuperado de http://observatorio. ministeriodesarrollosocial.gob.cl/casen/basededatos_ historico.php

Gobierno de Chile - Ministerio de Planificación. (2000). Casen 2000 - Encuesta de Caracterización Socioeconómica Nacional. Santiago de Chile: Gobierno de Chile. Recuperado de http:/ observatorio.ministeriodesarrollosocial.gob.cl/casen/ basededatos_historico.php

Heinrichs, D., Nuissl, H. \& Rodríguez, C. (2009). Dispersión urbana y nuevos desafíos para la gobernanza (metropolitana) en América Latina: el caso de Santiago de Chile. EURE, XXXV (104), 29-46. https://doi.org/10.4067/s0250-71612009000100002

Hidalgo, R. (2004). La vivienda social en Chile y la construcción del espacio urbano en el Santiago del siglo XX. Santiago de Chile: DIBAM - Centro de Investigaciones Barros Arana - Serie GEOlibros 3.

Hidalgo, R., Santana, D. \& Alvarado, V. (2016). Mitos, ideologías y utopías neoliberales de la producción del espacio: hacia una agenda de investigación alternativa. En R. Hidalgo, D. Santana, V. Alvarado, F. Arenas, A. Salazar, C. Valdebenito, \& L. Álvarez, En las costas del neoliberalismo. Naturaleza, urbanización $y$ producción inmobiliaria: experiencias en Chile y Argentina (pp. 24-66). Santiago de Chile: Serie GEOlibros $\mathrm{N}^{\circ} 23$.

Hipsher, P. (1996). Democratization and the decline of Urban Social Movements in Chile and Spain. Comparative Politics, 28(3), 273-297. http://dx.doi. org/10.2307/422208

Huneeus, C. (2016). El régimen de Pinochet. Santiago de Chile: Taurus.

Koppelman, C. (2018). "For Now, We Are in Waiting": Negotiating Time in Chile's Social Housing System. City\&Community, 17(2), 504-524. http://dx.doi. org/10.1111/cico.12301

La Tercera. (18 de octubre de 2019). Interior apunta a "grupos de delincuentes" tras evasiones masivas en el Metro. pág. 1.

La Tercera. (19 de octubre de 2019). Piñera decreta estado de emergencia en Santiago tras violencia desbordada. pág. 1.

Lombard, M. (2013). Citizen Participation in Urban Governance in the Context of Democratization: Evidence from Low-Income Neighbourhoods in Mexico. International Journal of Urban and Regional Research, 37(1), 135-150. http://dx.doi.org/10.1111/ j.1468-2427.2012.01175.x 
Lukes, S. (2014). El poder. Un enfoque radical. Madrid: Siglo XXI de España.

Ministerio de Desarrollo Social y Familia. (2017). Casen 2017. Santiago de Chile: Ministerio de Desarrollo Social y Familia - Observatorio Social. Recuperado de http://observatorio.ministeriodesarrollosocial.gob. cl/casen-multidimensional/casen/casen_2017.php

Murphy, E. (2015). For a proper home. Housing Rights in the Margins of Urban Chile, 1960-2010. Pittsburgh: University of Pittsburgh Press.

Observatorio Urbano. (2017). Viviendas por índice de hacinamiento. Santiago de Chile: Ministerio de Vivienda y Urbanismo - Observatorio Social. Recuperado de https://www.observatoriourbano.cl

Orellana, A. (2007). La gobernabilidad metropolitana: nuevos escenarios para el desarrollo urbano y territorial del Área Metropolitana de Santiago. En C. de Mattos \& R. Hidalgo, Santiago de Chile. Movilidad espacial y Reconfiguración Metropolitana (pp. 189-204). Santiago de Chile: Instituto de Estudios Urbanos - Instituto de Geografía - Pontificia Universidad Católica de Chile.

Özler, I. (2012). The Concertación and Homelessness in Chile: Market-based Housing Policies and Limited Popular Participation. Latin American Perspectives, 39(4), 53-70. http://dx.doi. org/10.1177/0094582X10397917

Paley, J. (2001). Marketing Democracy: Power and Social Movements in Post-Dictatorship Chile. California: University of California Press.

Paulsen-Espinoza, A. (2014). Negocios inmobiliarios, cambio socioespacial y contestación ciudadana en Santiago Poniente. En R. Hidalgo, \& M. Janoschka, La Ciudad Neoliberal. Gentrificación y exclusión en Santiago de Chile, Buenos Aires, Ciudad de México y Madrid. (pp. 87-113). Santiago de Chile: Santiago de Chile: Serie Geolibros $\mathrm{N}^{\circ} 19$, Instituto de Geografía, Pontificia Universidad Católica de Chile / Departamento de Ciencia Política y Relaciones Internacionales, Universidad Autónoma de Madrid.

Pierre, J. (1999). Models of urban governance - The institutional dimension of urban polities. Urban Affairs Review, 34(3), 372-396. http://dx.doi. org/10.1177/10780879922183988
Pierre, J. (2014). Can Urban Regimes Travel in Time and Space? Urban Regime Theory, Urban Governance Theory, and Comparative Urban Politics. Urban Affairs Review, 50(6), 864-889. http://dx.doi. org/10.1177/1078087413518175

Pírez, P. (2008). Gobernanza metropolitana, centralización jurisdiccional y relaciones políticas. En G. Yáñez, A. Orellana, O. Figueroa \& F. Arenas, Ciudad, Poder, Gobernanza (pp. 91-110). Santiago de Chile: Instituto de Estudios Urbano - Serie GEOlibros N 9 - PUC.

Prince, R. (2016). The spaces in between: Mobile policy and the topographies and topologies of the technocracy. Environment and Planning D Society \& Space, 34(3), 420-437. http://dx.doi. org/10.1177/0263775815618401

Puello-Socarrás, J. (2015). Neoliberalismo, antineoliberalismo., nuevo neoliberalismo. Episodios y trayectorias económico políticas suramericanas (1973-2015). En L. Rojas Villagra, Neoliberalismo en América Latina. Crisis, tendencias y alternativas (pp. 19-42). Asunción: CLACSO. Recuperado de http:// biblioteca.clacso.edu.ar/clacso/gt/20151203044203/ Neoliberalismo.pdf

Putri, P. (2019). Insurgent planner: Transgressing the technocratic state of postcolonial Jakarta. Urban Studies, 57(9), 1-21. http://dx.doi. org/10.1177/0042098019853499

Rancière, J. (2010). La noche de los proletarios. Buenos Aires: Tinta Limón.

Resolución 533. (13 de octubre de 1997). Fija procedimiento para prestación de servicios de asistencia técnica a programas de vivienda que indica. Santiago de Chile, Chile: Biblioteca del Congreso Nacional de Chile. Recuperado de https:// www.leychile.cl/N? $1=76791 \& f=2009-12-29 \& p=$

Rubio, R. (2006). Lecciones de la política de vivienda en Chile. Bitácora Urbano/Territorial, 1 (10), $197-$ 206. https://revistas.unal.edu.co/index.php/bitacora/ article/view/18722/19619

Rumié Rojo, S. (2019). Chicago Boys en Chile: neoliberalismo, saber experto y el auge de una nueva tecnocracia. Revista Mexicana de Ciencias Políticas y Sociales NuevaÉpoca,64(235), 139-164.http://dx.doi. org/10.22201/fcpys.2448492xe.2019.235.61782 
Sánchez, J. (2008). La gobernanza desde la óptica del poder y las escalas. En G. Yáñez, A. Orellana, O. Figueroa \& F. Arenas, Ciudad, Poder, Gobernanza (pp. 21-51). Santiago de Chile: Instituto de Estudios Urbanos y Territoriales - Colección RIDEAL - Serie GEOlibros $N^{\circ} 9$ - EURE Libros.

Sassen, S. (1998). Ciudades en la economía global: enfoques teóricos y metodológicos. EURE, 24(71), 5-25. https://doi.org/10.4067/s025071611998007100001

Savini, F. \& Raco, M. (2019). The rise of a new urban technocracy. En M. Raco, \& F. Savini, Planning and Knowledge. How new forms of technocracy are shaping contemporary cities (pp. 3-30). Bristol Chicago: Policy Press.

Schatz, L., \& Rogers, D. (2016). Participatory, technocratic and neoliberal planning: an untenable planning governance menage a trois. Australian Planner, 53(1), 37-45. http://dx.doi.org/10.1080/072 93682.2015.1135816

Sierra, L. (2006). Urbanismo por decreto: centralismo y confusión institucional en la ciudad chilena. En A. Galetovic, Santiago. Dónde estamos y hacia dónde vamos (pp. 299-328). Santiago de Chile: Centros de Estudios Públicos.

Silva, P. (1997). Ascenso tecnocrático y democracia en América Latina. Nueva Sociedad, 152, 68-77. Recuperado de https://www.nuso.org/media/articles/ downloads/2640_1.pdf

Silva, P. (2010). En el nombre de la razón. Tecnócratas $y$ política en Chile. Santiago de Chile: Ediciones Universidad Diego Portales.

Silva, P. (2011). Tecnocracia y gobernabilidad democrática en América Latina. En J. Guzmán León, Actores y desafios a la convivencia política en América Latina (pp. 19-48). Quito: FLACSO. Recuperado de https://biblio.flacsoandes.edu.ec/ libros/digital/53850.pdf

Sims, K. (2015). The Asian Development Bank and the production of poverty: Neoliberalism, technocratic modernization and land dispossession in the Greater Mekong Subregion. Singapore Journal of Tropical Geography, 36(1), 112-126. http://dx.doi. org/10.1111/sjtg.12093
Sundaram, J. \& Chowdhury, A. (2013). Buena gobernanza y desarrollo. En P. Chaves Giraldo, C. Prieto del Campo, \& R. Ramírez Gallegos, Crisis del capitalismo neoliberal, poder constituyente $y$ democracia real (pp. 441-456). Madrid: Traficantes de Sueños.

Swyngedouw, E. (2005). Governance Innovation and the Citizen: The Janus Face of Governance-beyondthe-state. Urban Studies, 42(11), 1991-2006. https:// doi.org/10.1080/00420980500279869

Swyngedouw, E. (2011). Interrogating postdemocratization: Reclaiming egalitarian political spaces. Political Geography, 30(7), 370-380. http:// dx.doi.org/10.1016/j.polgeo.2011.08.001

Swyngedouw, E. (2015). Despolitización. En G. D’Alisa, F. Demaría, \& G. Kallis, Decrecimiento. Vocabulario para una nueva era (págs. 149-154). Barcelona: Icaria.

Swyngedouw, E. (2018). Promises of the political. Insurgent cities in a Post-Political environment. Cambridge: MIT Press.

Sylvestre, M.-E., Blomley, N., \& Bellot, C. (2019). Red Zones. Criminal Law and the Territorial Governance of Marginalized People. Cambridge: Cambridge University Press. http://dx.doi. org/10.1017/97811316875544

Tapia, V. (2018). Geografías de la contención: el rol de las políticas de escala barrial en el Chile neoliberal. Scripta Nova. Revista Electrónica de Geografía y Ciencias Sociales, 22(592), 1-37. Recuperado de https://revistes.ub.edu/index.php/ScriptaNova/ article/view/20272

Valdivia, V. (2013). El Santiago de Ravinet. Despolitización y consolidación del proyecto dictatorial en el Chile de los noventa. Historia, 1(46)177-219. Recuperado de https://scielo.conicyt. cl/pdf/historia/v46n1/art06.pdf

Vicuña, M. (2013). El marco regulatorio en el contexto de la gestión empresarialista y la mercantilización del desarrollo urbano del Gran Santiago, Chile. Revista INVI, 28(78), 181-219. Recuperado de http://revistainvi.uchile.cl/index.php/INVI/article/ view/761/1100 
Villarreal González, D., \& Mignot, D. (2007). Metropolización, concentración económica y desigualdades espaciales en México y Francia. México D.F.: Universidad Autónoma Metropolitana - Unidad Xochimilco - División de Ciencias Sociales y Humanidades.

Williams Montoya, J., Hidalgo, R., Brand, P. \& Pérez, L. (2014). Metropolizaciones Colombia-Chile: Experiencias de Bogotá, Medellín, Santiago y Concepción. Medellín: Universidad Nacional de Colombia - Facultad de Arquitectura.

Zibechi, R.(2007). Territorios en resistencia. Cartografía politica de las periferias urbanas latinoamericanas. Buenos Aires: lavaca.

Zibechi, R. (2010). Progre-sismo. La domesticación de los conflictos sociales. Santiago de Chile: Editorial Quimantú.
Zunino, H. (2006). Power relations in Urban Decisionmaking: Neo-liberalism, "Techno-politicians" and Authoritarian Redevelopment in Santiago, Chile. Urban Studies, 43(10), 1825-1846. https://doi. org/10.1080/00420980600838184

Zunino, H. (2014). Penetración neoliberal en Chile: posibilidades y restricciones para la participación ciudadana. Revista de Geografia Espacios, 4(7), 7181. https://doi.org/10.25074/07197209.7.360

\section{Agradecimientos}

El autor agradece de sobremanera a los dirigentes y socios del Movimiento de Pobladores Ukamau por su amabilidad en acceder a las entrevistas, sus archivos y los espacios en los que ellos desarrollan sus actividades cotidianas. 